\title{
MEASUREMENT OF MASS FLOW RATE AS A COMPLEX FLOW PROBLEM
}

\author{
M. Kabaciński", S. Pochwała ${ }^{* *}$, J. Pospolita ${ }^{* * *}$, D. Krogulec ${ }^{\dagger}$
}

\begin{abstract}
The measurements of flow rates of fluids are some of the most common procedures applied in practice. Beside the standard examples of flow measurements, we often have to do with complex issues that occur in the relatively long sections of a straight pipeline. Such issues need to an individual approach to be taken. In such cases, it is useful to apply a mathematical flow modeling of a given flow system. The present paper presents two examples of such problems. These problems focus on an installation that is applied for feeding air into a coal mill. The results of the mathematical flow modeling of an installation provided a manner in which the location of a flowmeter can be established. Such a location provides a decrease of the measurement uncertainty as well as provides a manner in which the reliability of the flow system can be improved.
\end{abstract}

\section{Keywords: averaging Pitot tubes, flowmeter, CFD, measurement uncertainty}

\section{Introduction}

The analyses concerned with mass and volumetric flow rates form some of the most common types of measurements in the industrial practice. The number of the possible cases of such measurements applied in various branches of industry resulted in the development of a wide range of measurement techniques. As a consequence, considerable progress in the area of the design of flowmeters was possible. As a result, the measurements of the mass and volumetric rates can be performed within a wide range of the physical parameters of the fluids (Baker, 2000). The manufacturers of control and measurement apparatus produce and market flowmeters with a considerable measurement range, smaller measurement uncertainty and the scope of applications that provide reliable operation within a great range of the temperatures of the flow (Spitzer, 1996). The progress in the area of measurements of pressure and differential pressure forms one of the reasons for the popularity of the existing variety of averaging Pitot tubes (Pochwala et al., 2016, Kabacinski et al., 2011). The existing norms as well as the guidelines developed on the basis of works ordered by manufactures of equipment as well as studies in this area contain statements with the conditions that have to be fulfilled for the installation of a flowmeter (Chmielniak, 2008). In particular, norms contain details of the required straight runs of pipeline before and after a flowmeter corresponding to various types of obstacles, such as elbows, valves and throttles present in a system. Another problem is associated with transient states occurring in the flow (Pochwala et al., 2016), as well as occurrence of a second phase in the fluid flow (Borsuk et al., 2016). Such phenomena can generally affect the measurement uncertainty as well as reliability of the operation of a measurement system. The results of the research into transient states and second phase in the flow can be often applied in the power industry.

\footnotetext{
Adjunct prof. Mirosław Kabaciński, PhD.: Department of Thermal Engineering and Industrial Facilities, Opole University of Technology, 76 Prószkowska str.; 45-758, Opole; Poland, m.kabacinski@po.opole.pl

** Adjunct prof. Sławomir Pochwała, PhD.: Department of Thermal Engineering and Industrial Facilities, Opole University of Technology, 76 Prószkowska str.; 45-758, Opole; Poland, s.pochwala@po.opole.pl

*** Prof. Janusz Pospolita, PhD.: Department of Thermal Engineering and Industrial Facilities, Opole University of Technology, 76 Prószkowska str.; 45-758, Opole; Poland, j.pospolita@po.opole.pl

$\dagger \quad$ MSc. Damian Krogulec, PhD Student.: Department of Thermal Engineering and Industrial Facilities, Opole University of Technology, 76 Prószkowska str.; 45-758, Opole; Poland, d.krogulec@doktorant.po.opole.pl
} 
In particular, large boilers in power plants and their auxiliary equipment form the types of facilities in which the measurements of flow rates can be particularly difficult. These problems often occur in air channels with considerable diameters, often not in a circular shape. The existing installations do not provide adequate conditions for the occurrence of completely developed flow before a flowmeter. In addition, flowmeters can be subjected to contamination by fly ashes or temperature can form the reason for the impediments in air flow measurements. In such cases, the selection and location of the flowmeter can pose a problem, whose solution requires insight into the distribution of the velocities of the fluid flow in the system when various flow parameters occur in a given case. This poses an individual problem the solution of which can require a number of model studies. In addition, at this stage it is difficult to anticipate the level of the measurement uncertainty as well as to find out the details regarding the exploitation problems associated with a given type of measurement. Such cases call for a new approach to be taken with regard to a given measurement problem so as to provide a solution to a specific metrological problem. This also requires the knowledge that exceeds the conditions associated with the flowmeter. Below is a list with examples of such solutions derived from the practice in industry.

\section{Examples of complex issues related to gas flow rate measurements}

The first example deals with the measurement of amount of air that is routed into a coal mill. Air is routed through a DN700 pipeline from a mill fan in the conditions when considerable interference occurs in the flow. Subsequently, air is separated into two DN1000 channels, which extract the air passing through the mill below the grinding stage in a ball-ring mill. The layout of this flow system is presented in Fig. 1. For technology and installation-related considerations, it was possible to measure the flow rate of air through a mill only in this section. Due to the high temperature of the air flow, exceeding $320^{\circ} \mathrm{C}$ and the presence of solid particles in the flow, a decision was made to apply a flowmeter comprising an averaging a Pitot tube (Pochwala et al., 2017) and an installation that provides the conditions for the blow through the probe chamber performed with the purpose of cleaning it.

a)

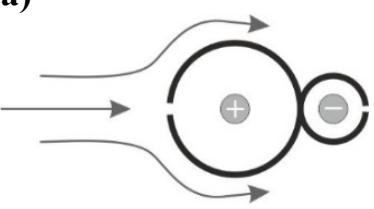

c)
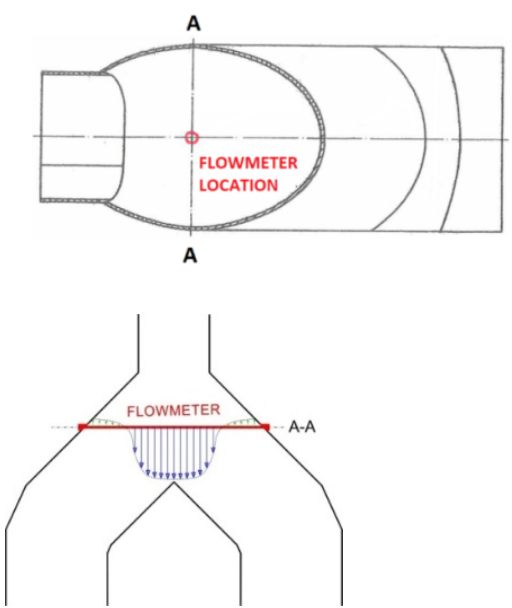

b)

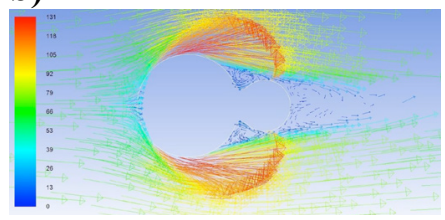

d)

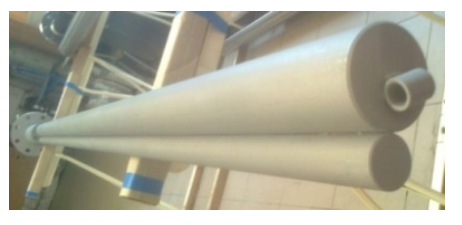

e)

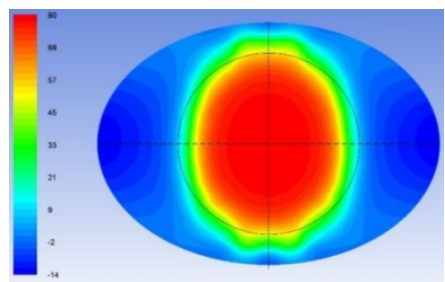

Fig. 1: Dual-cylinder flow averaging tube (a) applied for flow measurements, b) numerically determined streamlined flow across of the probe, $c$ ) analyzed system with the proposed location of the probe and the velocity distribution in the A-A section d) image of flow averaging tube, e) numerical results of velocity profile in the installation spot of the probe

The basic problem that needed to be solved was associated with providing an adequate location for the probe installation. Due to the lack of straight runs of pipeline as well as the occurrence of the disturbance of the flow velocity profile coupled with the high flow velocity (which can lead 
to the generation of probe vibrations), a decision was made to determine the installation location of the probe on the basis of a prior modeling of the flow in the circumstances that are similar to the real ones. The mathematical model was based on the fluid flow equations, continuity equations as well as $k-\omega$ equations for the flow turbulence model. The calculations were performed by application of the commercial Ansys Fluent software (ANSYS/Fluent. 2015). The boundary conditions were determined by the design of the flow system. The distribution of the velocity at the inlet and outlet was adopted on the basis of the numerical analysis of the geometry of the installation in the section which preceded the installation location of the flowmeter. Finally, the location was selected on the basis of the symmetry of the velocity distribution in the selected location measured for the entire variability of the flow rate. This selection was also governed by the values of the maximum and mean flow velocities and the range of the velocities in which the vibrations of the probe are generated. On the basis of the velocity distribution and locations of the pressure tapping bores, the measured differential pressure was established corresponding to the mean velocity in the section in which the probe was installed. The design of the measurement system applied for the regulation of the operating parameters of the milling assembly could be on the basis of the balance of air volume entering the boiler and the energy balance of the mill. As a result, satisfactory level of measurement uncertainty was established for this type of regulation system coupled with very good repeatability of the results of the conducted measurements.

Another system which applied numerical flow modeling is based on a crossoverpipe applied for feeding hot and cold air into three bowl coal mills. This system is presented in Fig. 2a and as developed on the basis of a manual that was provided to the current authors.

a)

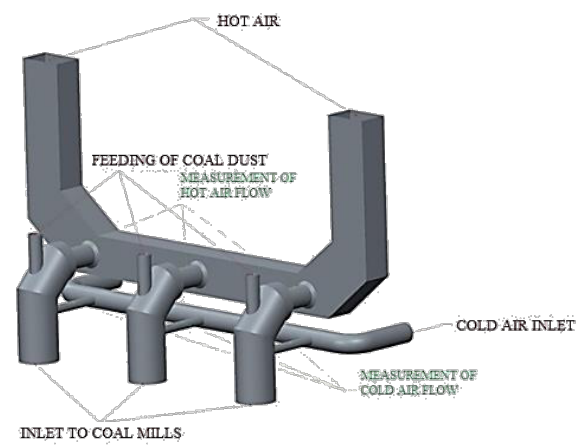

b)

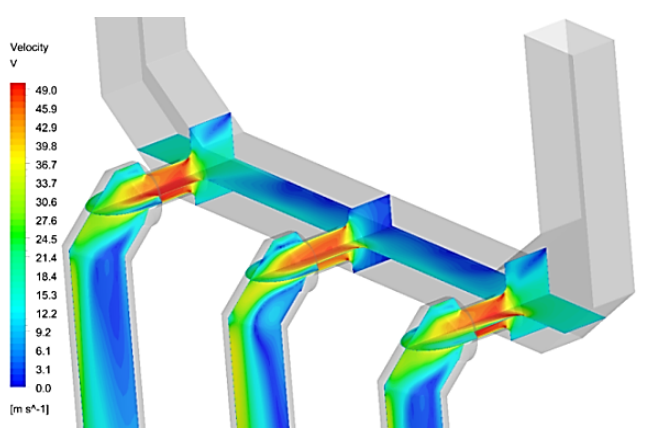

Fig.2: a) Diagram of the crossoverpipe applied for routing air into coal mills, b) Distribution of velocities in the vertical and horizontal section of the system (following system upgrade)

The flow modeling of the analyzed system was undertaken with the purpose of selecting an optimum location of a flowmeter comprising an averaging Pitot tube. The details of the velocity distributions in the analyzed cross-sections are presented on an example in Figs. 2b and 3. As a consequence of the analysis of the results, straightforward design changes were offered to be introduced into the system regarding the layout of the connection pipe joining the crossoverpipe to the inlet to the DN1200 pipeline. The resulting modifications involved the gas inlet and outlet combined with use of a longer straight section of the connection pipe. This simple modification contributed to the development of a considerably smoother velocity profile in the pipeline. This aspect also provided a manner in which the flow rate of the air could be performed by means of a flow averaging Pitot tube. The distribution of the velocity profile in the connection pipe prior to and following the upgrade of the system is presented in Fig. 3. The results in Fig.3 demonstrate that the upgrade of the system should provide the measurements of the air flow into coal mills. The uncertainty of the measurements conducted in such conditions should be at a satisfactory level so as to provide the application of the measured variable in the control system involving control of a mill. 


\section{Prior to design changes}
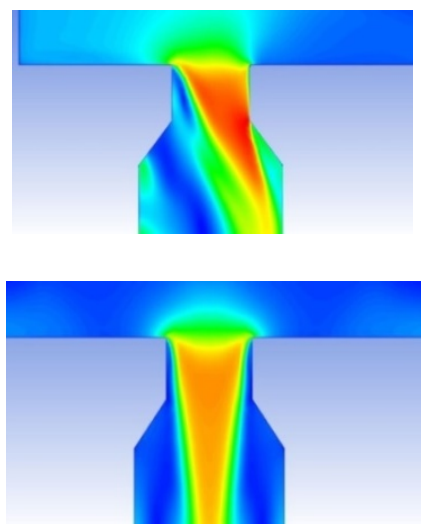

\section{Following design changes}
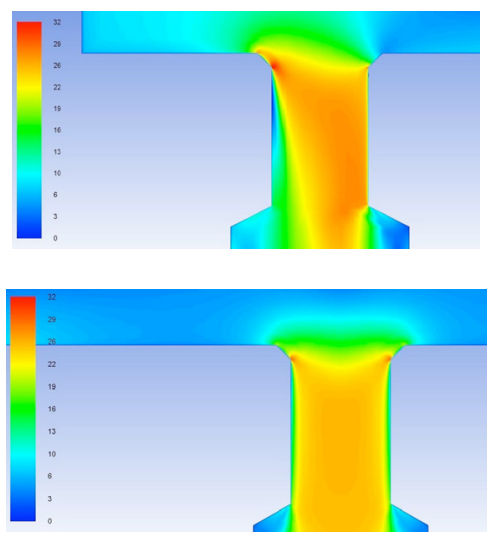

Fig. 3: Distribution of velocities in the selected section of the flow system before and after the implemented system upgrade

\section{Conclusions}

The results of this study offer grounds for the statement of the following conclusions:

1. The problems in industrial practice involving the measurements of flow rates often require a complex approach to be taken. The solution to such issues cannot be limited only to the selection of a flowmeter. The information that is needed to select an adequate location of a flowmeter needs to be based on research into the entire flow system. The system designed in such a manner requires thorough observations, balance calculations and calibration by application of other equipment applied for assessing measurement uncertainty.

2. A tool that finds application in solving such issues can be based on the mathematical flow modeling of an investigated flow system. Such an approach offers the possibility to determine the most suitable location for the installation of a flowmeter. The technique of mathematical modeling is only a tool that helps to optimize the measurement system and cannot offer a substitute to the control of the measurement system conducted by application of other methods. Mathematical modeling and numerical simulations can provide valuable guidelines associated with potential modernization of a flow system in terms of energy losses (pressure drop) limitation and occurrence of erosion. Modeling can offer other alternative measures applicable for the measurements of flow rates. For instance, the measured flow rate signal can be utilized for pressure drop estimation in a given section of a pipeline.

\section{References}

Baker, R. C. (2000). Flow Measurement Handbook. University of Cambridge.

Borsuk G., Pochwala S., Wydrych J. (2016) Numerical methods in processes of design and operation in pneumatic conweying systems. In: Engineering Mechanics 2016, IT AS CR, Prague, pp. 78-81.

Chmielniak, T., Kotowicz, J. \& Węcel, D. (2008). Experimental and numerical investigations of the averaging Pitot tube and analysis of installation effects on the flow coefficient. Flow Measurement and Instrumentation, No. 19, pp. 301-306.

Kabacinski M. \& Pospolita J. (2011) Experimental research into a new design of flow-averaging tube. Flow Measurement and Instrumentation. vol. 22, iss. 5, pp. 421-427.

Pochwala S. \& Pospolita J. (2016) Analysis of applicability of flow averaging pitot tubes in the areas of flow disturbance. Metrology and Measurements Systems, Vol. XXIII, No. 1, pp. 71-84

Pochwala S., Wydrych J., Borsuk G. (2017) The effect of velocity profile deformation of an averaging Pitot tube. In: Engineering Mechanics 2017, Brno University of Technology, Brno, pp. 790-793.

Spitzer D.W. (1996) Flow Measurement. Practical Guides for Measurement and Control, Instrument Society of America, United States of America.

ANSYS/Fluent, Fluid Dynamics Analysis Package. Fluid Dynamics International Inc., 2015. 